\title{
Optimizing the supercritical fluid extraction process of bioactive compounds from processed tomato skin by-products
}

\author{
Teresa Maria PELLICANÒ ${ }^{1}$, Vincenzo SICARI ${ }^{1}$, Monica Rosa LOIZZO ${ }^{2 \star}$ (D), Mariarosaria LEPORINI², \\ Tiziana FALCO ${ }^{2}$, Marco POIANA ${ }^{1}$
}

\begin{abstract}
A supercritical fluid extraction ( $\mathrm{SC}-\mathrm{CO}_{2}$ ) was used to extract high-quality oil from tomato skin by-products. The effects of pressure and extraction time on oil yield was investigated in the study. Lycopene and $\beta$-carotene content as well as $p$-coumaric acid, ferulic acid, caffeic acid, chlorogenic acid, vanillic acid, epicatechin, naringenin, catechin, quercetin and luteolin were estimated. The highest oil yield of $79.00 \%$ was obtained after $80 \mathrm{~min}$ with a pressure of $550 \mathrm{bar}$. The resulting oleoresin in carotenoids with lycopene and $\beta$-carotene content respectively of 0.86 and $1.5 \mathrm{mg} / 100 \mathrm{~g}$, this oleoresin was found to be the richest. Naringenin was the most abundant flavonoid identified with a maximum content in oleoresin extracted at 550 bar $(84.04 \mathrm{mg} / \mathrm{kg} \mathrm{DW})$ followed by caffeic acid $(26.60 \mathrm{mg} / \mathrm{kg} \mathrm{DW})$. A moderate radical scavenging potential was further observed. Overall, results highlight that pressure is a key parameter for the extraction bioactive oleoresin from tomato skin by-products.
\end{abstract}

Keywords: supercritical carbon dioxide extraction; tomato by-products; bioactive compounds.

Practical Application: Tomato processing waste as source of functional ingredients.

\section{Introduction}

Non-negligible amounts of various kinds of waste are generated in the vegetable processing industry. In particular, waste represents $2-3 \%$ of the raw material in the tomato processing industry, consisting mainly of peels (about 60\%) and seeds (around $40 \%$ ). Production companies generating this kind of waste due to disposal processes (Ćetković et al., 2012) are faced with the burden of additional costs. Several research studies have pointed out that tomato peels contain a high level of bioactive compounds including phenols, lycopene, ascorbic acid compared to their pulp and seeds (Vinha et al., 2014). Peels and seeds contribute particularly to $53 \%$ of the total amount of phenols, $52 \%$ of flavonoids, $48 \%$ of lycopene, $43 \%$ of ascorbic acid and $52 \%$ of the antioxidant activity occurring in tomatoes. These results demonstrate that the removal of peels and seeds during cooking or industrial processing leads to a significant loss of all the major antioxidants (Toor \& Savage, 2005). Lycopene represents the most promising compound among tomato antioxidants (Story et al., 2010; Kaliora et al., 2006; Visioli et al., 2003). The request for lycopene as a functional ingredient for nutraceutical products or for functional food formulations has increased dramatically over the past decade due to its acknowledged healthy properties. Since there is still no favourable synthetic process allowing for its production, lycopene extraction from natural plant matrices continues to be necessary. Currently, the most common methods for extracting lycopene from tomatoes or tomato processing residues are based on the use of organic solvent solvents (Machmudah et al., 2012). After the extraction procedure, lycopene is subjected to a long and expensive purification process that does not lead, however, to a high degree of purity. To overcome these drawbacks, new solvent-free and environmental friendly compatible extractions support the use of supercritical fluids such as carbon dioxide $\left(\mathrm{CO}_{2}\right)$ in order to obtain toxic-free solvent products (Amaral et al., $2018 \mathrm{a}, \mathrm{b})$. This technology is configured as an interesting alternative for the food industry due to the increased nutrient retention (Amaral et al., 2017).

Extraction by means of supercritical fluids is an alternative method to the traditional processes of fractional distillation, steam distillation, solvent extraction. Supercritical fluid extraction is based on the principle of a direct correlation between solvent power and density. In addition, the critical temperature of $\mathrm{CO}_{2}$ is close to the ambient temperature, so it is also capable of treating thermolabile substances (Nahar \& Sarker, 2012).

The aim of the present study was to optimize an extraction process of carotenoids and, in particular, of lycopene and $\beta$-carotene from tomato skins through the use of carbon dioxide as an extraction fluid in a supercritical state. Antioxidant activity and bioactive compound content were further determined.

\section{Materials and methods}

\subsection{Chemicals}

Standards of lycopene, $\beta$-carotene, $p$-coumaric acid, ferulic acid, caffeic acid, chlorogenic acid, vanillic acid, epicatechin, naringenin, catechin, quercetin, and luteolin were obtained from Extrasynthese (Genay-France). ABTS [2,2'-azinobis 
(3-ethylbenzothiazoline-6-sulfonate)], 2,2-diphenyl-1-picryl hydrazyl (DPPH), 6-Hydroxy-2, 5, 7, 8-tetramethyl-2-carboxylic acid, 97\% (Trolox) were purchased from Sigma-Aldrich Chem. Co. (Milan, Italy). All solvents and other reagents used were of HPLC grade and were purchased from Carlo Erba Reagents (Milan, Italy).

\subsection{Materials}

The tomato cultivars used in the current research were of the San Marzano type, named "Docet" "Ercole", "Fuzzer", "Herdon", "Komolix", "Player" and "Ulisse" due to their oblong shape, which are grown as field crops in the Southern Italian Regions of Campania and Apulia. These cultivars were chosen as they are commonly used in the tomato processing industry, where their separation is extremely difficult since they continuously reach the technological plant from different tomato plantations. Although the different cultivars are crushed together, this is not an influential factor for the present research which focuses on the processing conditions. Tomato lots were, in fact, processed with a treatment at $65-80^{\circ} \mathrm{C}$. Tomatoes were chopped beforehand to separate the pulp from seeds and peels and then floatation was conducted to separate the latter two. Peels were exposed to sunlight $(12 \mathrm{~h})$ to evaporate the majority of the water and oven-heating was applied at $40-50^{\circ} \mathrm{C}(24 \mathrm{~h})$ to evaporate residual humidity. Tomato skins were dehydrated to constant weight using a Christ ALPHA 2-4 LSC freeze-dryer (Martin Christ Gefriertrocknungsanlagen $\mathrm{GmbH}$, Osterode am Harz, Germany). Dried skins were homogenized in a laboratory ultra-centrifugal mill (ZM200, Retsch GmbH, Haan, Germany) through 35 mesh (350 $\mu \mathrm{m}$ sieves).

\subsection{Supercritical- $\mathrm{CO}_{2}$ extraction ( $\mathrm{SC}-\mathrm{CO}_{2}$ )}

Super Critical- $\mathrm{CO}_{2}$ extraction $\left(\mathrm{SC}-\mathrm{CO}_{2}\right.$ ) was carried out using a laboratory apparatus (Speed SFE system, Applied Separations, Allentown, PA, USA) fitted with a $25 \mathrm{~mL}$ stainless-steel extraction vessel $(\varnothing=1 \mathrm{~cm} ; \mathrm{h}=25 \mathrm{~cm})$. An aliquot of $18 \mathrm{~g}$ of raw material, packed into the vessel, was used for extraction which lasted between 20-80 min. Temperature, carbon dioxide flow rate and extraction time were kept constant respectively at $60{ }^{\circ} \mathrm{C}$ and $2 \mathrm{~mL} / \mathrm{min}$, while pressure was varied between 350,450 and 550 bar. The oil yield percentage was calculated. The extracted oils were stored under an enriched $\mathrm{CO}_{2}$ atmosphere and protected from light at $-20{ }^{\circ} \mathrm{C}$ until further analyses. Each extraction was repeated at least three times.

\subsection{Spectrophotometric determination of carotenoids in tomato by-products oil}

As Fish et al. (2002). report, lycopene and $\beta$-carotene contents in tomato by-products were determined using an UV-Vis spectrophotometer (Agilent 8453 Technologies, Italy). To minimize the interference from other carotenoids, the concentration of lycopene was calculated at $\lambda=503 \mathrm{~nm}$ using the molar extinction coefficient $\varepsilon=17.2 \times 10^{4} \mathrm{M}^{-1} \mathrm{~cm}^{-1}$. $\beta$-carotene absorbance was measured at $\lambda=450 \mathrm{~nm}$ and quantification was carried out using a standard curve. All analyses were made in triplicate and results were expressed as mean \pm standard deviation (SD).

\subsection{RP-HPLC/DAD determination of bioactive compounds}

$p$-Coumaric acid, ferulic acid, caffeic acid, chlorogenic acid, vanillic acid, luteolin, epicatechin, naringenin, catechin, and quercetin were selected as maker and quantified by HPLC in oleoresins extracted from tomato peels by supercritical fluid at a different pressure. A Knauer (Asi Advanced Scientific Instruments, Berlin, Germany) HPLC system, equipped with two pumps Smartiline Pump 1000, a Rheodyne injection valve $(20 \mu \mathrm{L})$ and a photodiode array detector UV/VIS with a semi-microcell, was used. Compounds were separated on a TSK gel ODS-100 V (TOSOH Bioscience, Germany) column $(250 \mathrm{~mm} \times 3.0$ I.D.; $3 \mu \mathrm{m})$ at $30^{\circ} \mathrm{C}$ and the flow rate used was $0.5 \mathrm{~mL} \mathrm{~min}^{-1}$.

The mobile phase consisted of water/formic acid (99.9:0.1, v/v; solvent A) and acetonitrile/formic acid (99.9:0.1, v/v; solvent B) and the gradient profile was as follows: 0.01-20.00 $\min 5 \% \mathrm{~B}$ isocratic; $20.01-50.00 \mathrm{~min}, 5-40 \% \mathrm{~B}$; $50.01-55.00 \mathrm{~min}, 40-95 \% \mathrm{~B}$; 55.01-60.00 $\min 95 \%$ B isocratic.

\subsection{Evaluation of radical scavenging activity of $\mathrm{SC}-\mathrm{CO}_{2}$ oils}

The radical scavenging potential of $\mathrm{SC}-\mathrm{CO}_{2}$ was investigated by means of DPPH and ABTS radical assays. The DPPH test was assessed following the method previously reported (Brand-Williams et al., 1995). An aliquot of $2.5 \mathrm{~mL}$ of $0.06 \mathrm{mM}$ $\mathrm{DPPH}$. solution was added to $20 \mu \mathrm{L}$ of oleoresin. Absorbances at $\mathrm{t}_{0}$ and $\mathrm{t}_{5}$ were measured at $\lambda=515 \mathrm{~nm}$ using a UV-Vis Agilent 8453 spectrophotometer (Agilent Technologies, Italy). Trolox was used as a standard antioxidant and tomato skin oil activity was expressed in $\mathrm{mM}$ of Trolox equivalents (TE).

The ABTS (2, 2'-azinobis-3-ethylbenzothiazoline-6-sulfonate) radical test was carried out as described by Re et al. (1999). The radical was generated by mixing $7 \mathrm{mM}$ of ABTS and $\mathrm{K}_{2} \mathrm{~S}_{2} \mathrm{O}_{8} 140 \mathrm{mM}$ and followed by storage in the dark at room temperature for $16 \mathrm{~h}$ before use. The mixture was diluted (1:80) with ethanol to give an absorbance of 0.70 at $\lambda=734 \mathrm{~nm}$. An aliquot of $50 \mu \mathrm{L}$ of sample extract was added to $950 \mathrm{~mL}$ of ABTS solution. Trolox was used as a control and tomato skin oil activity was expressed in $\mathrm{mM}$ of TE.

\subsection{Statistical analysis}

Results were expressed as mean \pm SD of three replicates. All data were analyzed using one-way analysis of variance (ANOVA) with SPSS 17.0 (SPSS Inc., Chicago, IL, USA) statistical software. Significant differences were calculated according to Duncan's multiple range tests. Differences at $P<0.05$ were considered to be statistically significant while at $P<0.01$ were considered to be highly significant. Studies of the Pearson's correlation coefficient $(r)$ and linear regression, assessment of repeatability, calculation of average and relative standard deviation were performed using Microsoft Excel 2010 software. Principal Component Analysis (PCA) were applied through the use of SPSS software for Windows, version 15.0 (Chicago, IL, USA). 


\section{Results and discussion}

\subsection{Effect of extraction parameters on carotenoids}

This research investigated the effect of pressure and extraction time on the recovery of lycopene, $\beta$-carotene and phenolic compounds from tomato skin by-products. In the case of extraction with supercritical $\mathrm{CO}_{2}$, temperature appears to be one of the most important parameters for yielding the target compound. In the specific case of lycopene extraction, different research studies indicate temperature as a parameter of fundamental importance in order to increase the yield of the extract (Reverchon \& De Marco, 2006; Egydio et al., 2010; Konar et al., 2012; Yi et al., 2009). At the temperature of $80^{\circ} \mathrm{C}$, lycopene solubility in supercritical $\mathrm{CO}_{2}$ showed a decrease, probably due to its thermal degradation. For this reason, the decision to operate at $60{ }^{\circ} \mathrm{C}$ was made. Lycopene recovery is reported to have increased slightly when the temperature rose from 40 to $60^{\circ} \mathrm{C}$ and persisted almost the same before reaching $80{ }^{\circ} \mathrm{C}$. Pressure effects on lycopene extraction are similar to temperature ones. Literature data show that an increase in supercritical carbon dioxide pressure causes an increase in the amount of extracted lycopene (Reverchon \& De Marco, 2006; Yi et al., 2009; Nobre et al., 2012). The level of lycopene at a higher pressure is due to the increased density of $\mathrm{SC}-\mathrm{CO}_{2}$ as a result of a greater interaction between the lycopene molecule and the supercritical carbon dioxide (Yi et al., 2009; Baysal et al., 2000). The use of different pressure values did not result in a difference in extraction yield with values of 3.60, 3.68 and $4.21 \%$ after 60 minutes for pressure of 350, 450 and 550 bar respectively (Table 1, Figure 1).

After 80 minutes, the achievement of a plateau with the maximum yield $(0.79 \mathrm{~g})$ at 550 bar was observed.

Table 1. Effect of extraction time on extraction yield at different pressure.

\begin{tabular}{|c|c|c|c|}
\hline \multirow{3}{*}{ Extraction time } & \multicolumn{3}{|c|}{ Extraction Yield (g) } \\
\hline & A & B & $\mathrm{C}$ \\
\hline & $350 \mathrm{Bar}$ & $450 \mathrm{Bar}$ & $550 \mathrm{Bar}$ \\
\hline 0 & 0.00 & 0.00 & 0.00 \\
\hline 20 & 0.37 & 0.57 & 0.67 \\
\hline 40 & 0.60 & 0.64 & 0.74 \\
\hline 60 & 0.65 & 0.66 & 0.76 \\
\hline 80 & 0.67 & 0.68 & 0.79 \\
\hline
\end{tabular}

Data are reported as mean \pm standard deviation $(n=3)$.

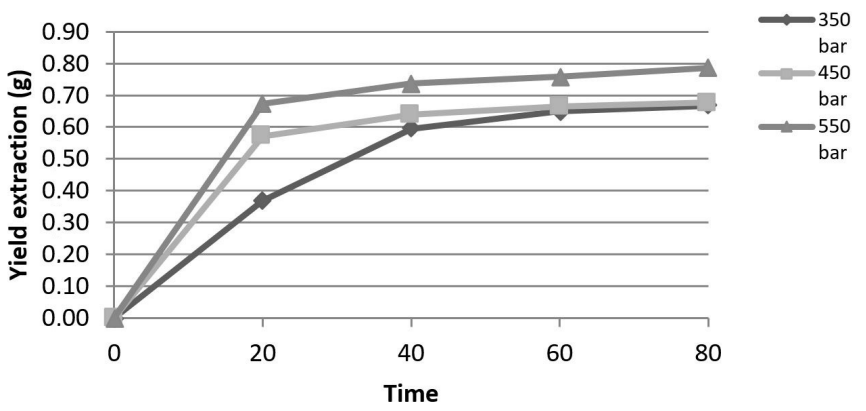

Figure 1. Extraction rate curves for tomato skin oil at $60^{\circ} \mathrm{C}$ as a function of extraction pressure.
According to our data, Kehili et al. (2017) reported that the recovery of oleoresin seems to increase with pressure values respectively of 4.86 and $5.56 \%$ at 400 and 500 bar and a temperature value of $60^{\circ} \mathrm{C}$ with an extraction time of 105 minutes. Evolution of the pressure effect on $\beta$-carotene and lycopene extraction (Table 2) showed that no significant differences occurred at 350 and 450 bar. Nevertheless, the application of 550 bar resulted in an increase of carotenoid content with values respectively of 0.86 and $1.5 \mathrm{mg} / 100 \mathrm{~g}$ FW.

These data diverge from those reported by Kehili et al. (2017), who pointed out a correlation between pressure and $\beta$-carotene without any effect on lycopene. Nobre et al. (2012) investigated the pressure and temperature effects on lycopene extraction. Carotenoid recovery increases with pressure and rises drastically when pressure increases from 200 to 300 bar, which is expected due to the increase in the solvent density with pressure (Machmudah et al., 2012). According to some authors, the rise in temperature at constant pressure determines an increase in the vapour pressure of lycopene (Reverchon \& De Marco, 2006; Egydio et al., 2010; Sabio et al., 2003; Saldana et al., 2002; Rozzi et al., 2002) which, in turn, determines greater solubility

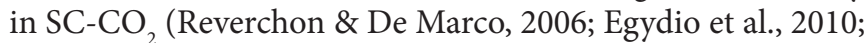
Sabio et al., 2003). Ultimately, we can claim that lycopene increase or decrease is mainly dependent on the interaction between pressure and temperature. In fact, the higher density of the SC-CO2 that occurs with the increase in pressure and consequently the greater extraction of lycopene, determines a defence of the solvent power following an increase in temperature. The density of SC-CO2 can decrease with an increase in temperature while keeping the pressure constant, but the density decrease becomes smaller at high pressures (Saldana et al., 2002; Rozzi et al., 2002). Genival et al. (2008) found that an increase in temperature at high pressures led to an increase in lycopene yield, while the lycopene yield decreased with increasing temperature at lower pressures. Lycopene solubility in $\mathrm{SC}-\mathrm{CO}_{2}$ and consequently its retention increase when temperature and pressure parameters are both increased (De la Fuente et al., 2006; Topal et al., 2006).

\subsection{The effect of extraction parameters on phenolics}

Analysis of the influence of applying a different pressure on phenolic acids generally revealed that their extraction is strictly connected to the pressure applied. An increase in pressure from 350 to 550 bar resulted, in fact, in a 1.56-time high extraction yield for all except for caffeic acid. A 1.94-time high extraction performance was obtained by using the application of $550 \mathrm{bar}$ in comparison to lower pressure on ferulic acid. A similar trend was observed also for $p$-coumaric acid. No significant differences were recorded for pressure on chlorogenic acid content (Table 3 ).

Table 2. Comparative $\beta$-carotene and lycopene content in oils obtained at different pressure. Data are expressed as mg/100 g DW.

\begin{tabular}{ccc}
\hline & Lycopen & $\beta$-Caroten \\
\hline A & $0.50 \pm 0.05$ & $1.3 \pm 0.1$ \\
B & $0.62 \pm 0.04$ & $1.3 \pm 0.4$ \\
C & $0.86 \pm 0.06$ & $1.5 \pm 0.4$ \\
\hline
\end{tabular}

Data are reported as mean \pm standard deviation $(n=3)$. 
Pellicanò et al.

Table 3. Comparative phenolic profile in oils obtained at different pressure. Data are expressed as mg/kg DW.

\begin{tabular}{ccccccccccc}
\hline & Vanillic acid & Caffeic acid & Ferulic acid & $\begin{array}{c}\text { P-Coumaric } \\
\text { acid }\end{array}$ & $\begin{array}{c}\text { Chlorogenic } \\
\text { acid }\end{array}$ & Quercetin & Epicatechin & Catechin & Naringenin & Luteolin \\
\hline A & $1.74 \pm 0.02$ & $16.32 \pm 0.08$ & $4.06 \pm 0.02$ & $5.52 \pm 0.24$ & $4.02 \pm 0.08$ & $6.71 \pm 0.13$ & $1.08 \pm 0.05$ & $3.12 \pm 0.04$ & $62.33 \pm 0.15$ & $0.24 \pm 0.05$ \\
B & $1.61 \pm 0.09$ & $26.8 \pm 0.04$ & $5.05 \pm 0.07$ & $6.55 \pm 0.06$ & $3.49 \pm 0.57$ & $6.58 \pm 0.05$ & $2.37 \pm 0.06$ & $3.57 \pm 0.03$ & $77.62 \pm 0.08$ & $0.16 \pm 0.03$ \\
C & $2.71 \pm 0.05$ & $26.60 \pm 0.05$ & $7.88 \pm 0.04$ & $10.05 \pm 0.06$ & $4.05 \pm 0.07$ & $6.85 \pm 0.06$ & $2.83 \pm 0.03$ & $4.02 \pm 0.05$ & $84.04 \pm 0.10$ & $0.27 \pm 0.06$ \\
\hline \multicolumn{7}{l}{ Data are reported as mean \pm standard deviation $(n=3)}$.
\end{tabular}

High content of chlorogenic acid has been also found in tomato processing waste by Nour et al. (2018). The effect of applying pressure on phenolic extraction was monitored using quercetin, epicatechin, catechin, naringenin and luteolin $s$ markers. Data analysis highlighted how the increase in pressure led to a rise in the extraction performance of both epicatechin (respectively $1.08 \mathrm{mg} / \mathrm{kg}$ DW vs $2.83 \mathrm{mg} / \mathrm{kg}$ DW at 350 and 550 bar) and catechin (respectively $3.12 \mathrm{mg} / \mathrm{kg}$ DW vs $4.22 \mathrm{mg} / \mathrm{kg}$ DW at 350 and $550 \mathrm{bar}$ ). Among the flavonoids selected, only naringenin extraction seems to be conditioned by pressure (1.33-time higher at 550 bar). Tomato phenolic content varies considerably between skin and pulp; tomato skin contains a higher concentration of phenolic compounds. George et al. (2004) studied the antioxidant fraction in 12 tomato genotypes, and reported that tomato skin contains significant amounts of polyphenols and ascorbic acid with a phenolic content ranging from 10.4 to 40.0 catechin $\mathrm{mg} / 100 \mathrm{~g}$ FW. A similar observation was made by Toor \& Savage (2005) who reported a total phenolic content of $29.1 \mathrm{mg}$ GAE/100 g FW. Kalogeropoulos et al. (2012) investigated the HPLC profile of the whole tomato and its by-products (pomace constituted by skin and seeds) and underlined how hydroxycinnamic acids predominated in the whole fruit, whereas flavonoids prevail in the pomace rather than glycosylated compounds. According to our results, naringenin was the main abundant compound $(328.6 \mathrm{mg} / \mathrm{kg} \mathrm{DW})$. The high flavonoid content (98\%) of tomato skin has been previously reported also by Stewart et al. (2000) who analysed 20 different tomato varieties.

\subsection{Radical scavenging potential of tomato oleoresin}

The antioxidant potential was measured by using the two different radical scavenging tests DPPH and ABTS. Samples did not show any difference due to the method applied and an increase in the TEAC value depending on the pressure with a high value at 550 bar (respectively 0.08 and $0.11 \mathrm{mM}$ Trolox for DPPH and ABTS tests) (Table 4).

It is worth noting that no correlations were found between the radical scavenging potential and the content of phenols or carotenoids. The activity is, in fact, no longer high in the extract obtained at 550 bar and characterized by the highest content of bioactive compounds. This evidence is consistent with that reported by Kehili et al. (2017) who observed the highest DPPH radical scavenging activity in oleoresin samples extracted under relatively mild conditions of pressure and temperature (300 bar and $50{ }^{\circ} \mathrm{C}$ ). This evidence is likely the consequence of a greater conservation of bioactive compounds when mild operating conditions are used as in our study. The radical scavenging potential of tomato skin product after a different
Table 4. Radical scavenging potential of oils obtained at different pressure.

\begin{tabular}{cccc}
\hline & DPPH & & ABTS \\
\cline { 2 - 2 } A & $(\mathrm{mM}$ Trolox $)$ & & $(\mathrm{mM}$ Trolox $)$ \\
B & $0.06 \pm 0.006$ & & $0.09 \pm 0.04$ \\
C & $0.07 \pm 0.002$ & & $0.10 \pm 0.02$ \\
\hline
\end{tabular}

Data are reported as mean \pm standard deviation $(n=3)$.

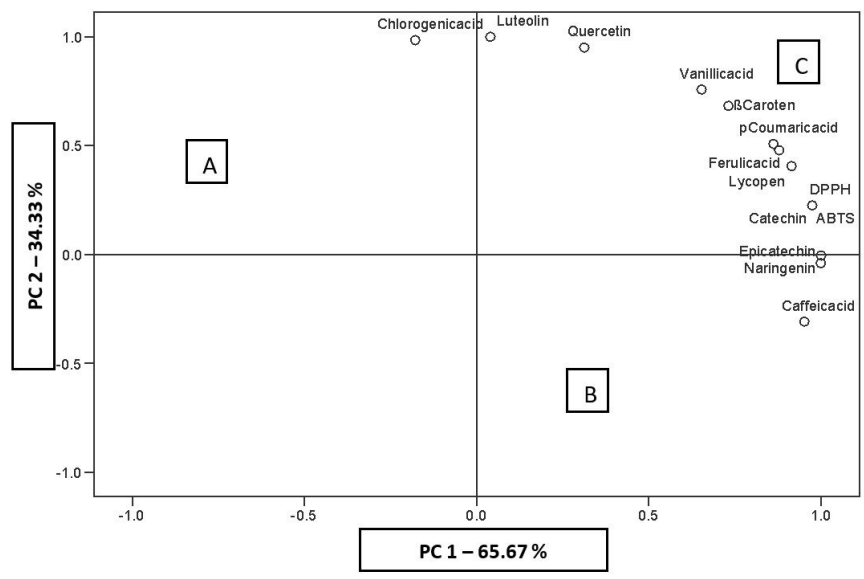

Figure 2. Two-dimensional map representation of PCA distribution of variables and distribution of samples. (A) 350 bar; (B) 450 bar; (C) 550 bar.

drying process was demonstrated. Samples showed a percentage of DPPH radical ranging from 0.19 to 7.63 for $1 \mathrm{~g}$ of DW extract (Albanese et al., 2014).

\subsection{Multivariate analysis}

PCA was performed with all parameters obtained from the determination of antioxidant activity through DPPH, ABTS and individual phenolic compounds quantified by HPLC-DAD. After the statistical analysis of data, the PCA model retained two principal components (PC), which explained $100 \%$ of the total variability (PC1 explains about $65,67 \%$ and $\mathrm{PC} 2$ about $34.33 \%$ ). The loading plots of the first two principal components are shown in Figure 2.

PC1 correlated positively with lycopen and $\beta$-carotene, vanillic acid, caffeic acid, ferulic acid,p-coumaric acid, epicatechin, catechin, naringenin, DPPH and ABTS. Principal Component 1 (PC1) was inversely correlated with chlorogenic acid. PCA showed that tomato skin samples extracted by SC- $\mathrm{CO}_{2}$ at 550 bar and $80 \mathrm{~min}$ were characterized by a higher content of phenolic compounds with great antioxidant activity. 


\section{Conclusion}

The effect of different pressures on carotenoids and phenols $\mathrm{SC}-\mathrm{CO}_{2}$ extraction from tomato skin by-products was investigated. If the extraction conditions exceed optimal operating conditions, this may result in a decrease in the recovery of phytochemicals or in the bioactivity of the extract. It is interesting to note that in applying maximum pressure, there is a double effect, namely a major phytochemicals recovery was observed together with a negative impact on antioxidant activity. These results prove that pressure can be considered a key parameter for the $\mathrm{SC}-\mathrm{CO}_{2}$ extraction of bioactive oleoresin from tomato skin by-products.

\section{Acknowledgements}

Authors wish to thank Programma Operativo Nazionale “Ricerca e Competitività 2007-2013” PON 01_01397 Tom \& Cherry for support this research project and Prof. Anna Franca Plastina, Associate Professor of English language at Department of Pharmacy, Health and Nutritional Sciences, University of Calabria for editing and review service.

\section{References}

Albanese, D., Adiletta, G., D'Acunto, M., Cinquanta, L., \& Di Matteo, M. (2014). Tomato peel drying and carotenoids stability of the extracts. International Journal of Food Science \& Technology, 49(11), 2458-2463. http://dx.doi.org/10.1111/ijfs.12602.

Amaral, G. V., Silva, E. K., Cavalcanti, R. N., Cappato, L. P., Guimaraes, J. T., Alvarenga, V. O., Esmerino, E. A., Portela, J. B., Sant' Ana, A. S., Freitas, M. Q., Silva, M. C., Raices, R. S. L., Meireles, M. A. A., \& Cruz, A. G. (2017). Dairy processing using supercritical carbon dioxide technology: theoretical fundamentals, quality and safety aspects. Trends in Food Science \& Technology, 64, 94-101. http:// dx.doi.org/10.1016/j.tifs.2017.04.004.

Amaral, G. V., Silva, E. K., Cavalcanti, R. N., Martins, C. P. C., Andrade, L. G. Z. S., Moraes, J., Alvarenga, V. O., Guimarães, J. T., Esmerino, E. A., Freitas, M. Q., Silva, M. C., Raices, R. S. L., Sant' Ana, A. S., Meireles, M. A. A., \& Cruz, A. G. (2018a). Whey-grape juice drink processed by supercritical carbon dioxide technology: physicochemical characteristics, bioactive compounds and volatile profile. Food Chemistry, 239, 697-703. http://dx.doi.org/10.1016/j. foodchem.2017.07.003. PMid:28873624.

Amaral, G. V., Silva, E. K., Costa, A. L. R., Alvarenga, V. O., Cavalcanti, R. N., Esmerino, E. A., Guimaraes, J. T., Freitas, M. Q., Sant'Ana, A. S., Cunha, R. L., Moraes, J., Silva, M. C., Meireles, M. A. A., \& Cruz, A. G. (2018b). Whey-grape juice drink processed by supercritical carbon dioxide technology: physical properties and sensory acceptance. Lebensmittel-Wissenschaft + Technologie, 92, 80-86. http://dx.doi.org/10.1016/j.lwt.2018.02.005.

Baysal, T., Ersus, S., \& Starmans, D. A. J. (2000). Supercritical $\mathrm{CO}_{2}$ extraction of beta-carotene and lycopene from tomato paste waste. Journal of Agricultural and Food Chemistry, 48(11), 5507-5511. http://dx.doi.org/10.1021/jf000311t. PMid:11087510.

Brand-Williams, W., Cuvelier, M. E., \& Berset, C. (1995). Use of a free radical method to evaluate antioxidant activity. LebensmittelWissenschaft + Technologie, 28(1), 25-30. http://dx.doi.org/10.1016/ S0023-6438(95)80008-5.

Ćetković, G., Savatović, S., Čanadanović-Brunet, J., Djilas, S., Vulić, J., Mandić, A., \& Četojević-Simin, D. (2012). Valorisation of phenolic composition, antioxidant and cell growth activities of tomato waste.
Food Chemistry, 133(3), 938-945. http://dx.doi.org/10.1016/j. foodchem.2012.02.007.

De la Fuente, J. C., Oyarzun, B., Quezada, N., \& Del Valle, J. M. (2006). Solubility of carotenoid pigments (lycopene and astaxanthin) in supercritical carbon dioxide. Fluid Phase Equilibria, 247(1-2), 9095. http://dx.doi.org/10.1016/j.fluid.2006.05.031.

Egydio, J. A., Moraes, A. M., \& Rosa, P. T. V. (2010). Supercritical fluid extraction of lycopene from tomato juice and characterization of its antioxidation activity. The Journal of Supercritical Fluids, 54(2), 159-164. http://dx.doi.org/10.1016/j.supflu.2010.04.009.

Fish, W. W., Perkins-Veazie, P., \& Collins, J. K. (2002). A quantitative assay for lycopene that utilizes reduced volumes of organic solvents. Journal of Food Composition and Analysis, 15(3), 309-317. http:// dx.doi.org/10.1006/jfca.2002.1069.

Genival, L. Fo., De Rosso, V., Meireles, M. A. M., Rosa, P. T. V., Oliveira, A., Mercadante, A., \& Cabral, F. (2008). Supercritical CO extraction of carotenoids from pitanga fruits (Eugenia uniflora L.). The Journal of Supercritical Fluids, 46(1), 33-39. http://dx.doi.org/10.1016/j. supflu.2008.02.014.

George, B., Kaur, C., Khurdiya, D. S., \& Kapoor, H. C. (2004). Antioxidants in tomato (Lycopersium esculentum) as a function of genotype. Food Chemistry, 84(1), 45-51. http://dx.doi.org/10.1016/ S0308-8146(03)00165-1.

Kaliora, A. C., Dedoussis, G. V., \& Schmidt, H. (2006). Dietary antioxidants in preventing atherogenesis. Atherosclerosis, 187(1), 1-17. http:// dx.doi.org/10.1016/j.atherosclerosis.2005.11.001. PMid:16313912.

Kalogeropoulos, N., Chiou, A., Pyriochou, V., Peristeraki, A., \& Karathanos, V. (2012). Bioactive phytochemicals in industrial tomatoes and their processing byproducts. Lebensmittel-Wissenschaft + Technologie, 49(2), 213-216. http://dx.doi.org/10.1016/j.lwt.2011.12.036.

Kehili, M., Kammlott, M., Choura, S., Zammel, A., Zetzl, C., Smirnova, I., Allouche, N., \& Sayadi, S. (2017). Supercritical $\mathrm{CO}_{2}$ extraction and antioxidant activity of lycopene and $\beta$-carotene-enriched oleoresin from tomato (Lycopersicum esculentum L.) peels by-product of a Tunisian industry. Food and Bioproducts Processing, 102, 340-349. http://dx.doi.org/10.1016/j.fbp.2017.02.002.

Konar, N., Haspolat, I., Poyrazoğlu, E. S., Demir, K., \& Artık, N. (2012). A review on supercritical fluid extraction (SFE) of lycopene from tomato and tomato products. Karaelmas Science Engineering Journal, 2(1), 69-75. http://dx.doi.org/10.7212/zkufbd.v2i1.81.

Machmudah, S., Zakaria Winardi, S., Sasaki, M., Goto, M., Kusumoto, N., \& Hayakawa, K. (2012). Lycopene extraction from tomato peel by-product containing tomato seed using supercritical carbon dioxide. Journal of Food Engineering, 108(2), 290-296. http://dx.doi. org/10.1016/j.jfoodeng.2011.08.012.

Nahar, L., \& Sarker, S. D. (2012). Supercritical fluid extraction in natural products analyses. Methods in Molecular Biology, 864, 43-74. http:// dx.doi.org/10.1007/978-1-61779-624-1_3. PMid:22367893.

Nobre, B. P., Gouveia, L., Matos, P. G., Cristino, A. F., Palavra, A. F., \& Mendes, R. L. (2012). Supercritical extraction of lycopene from tomato industrial wastes with ethane. Molecules, 17(7), 8397-8407. http://dx.doi.org/10.3390/molecules17078397. PMid:22785267.

Nour, V., Panaite, T. D., Ropota, M., Turcu, R., Trandafir, I., \& Corbu, A. R. (2018). Nutritional and bioactive compounds in dried tomato processing waste. CYTA: Journal of Food, 16(1), 222-229. http:// dx.doi.org/10.1080/19476337.2017.1383514.

Re, R., Pellegrini, N., Proteggente, A., Pannala, A., Yang, M., \& RiceEvans, C. (1999). Antioxidant activity applying an improved ABTS radical cation decolorization assay. Free Radical Biology \& Medicine, 
26(9-10), 1231-1237. http://dx.doi.org/10.1016/S0891-5849(98)003153. PMid:10381194.

Reverchon, E., \& De Marco, I. (2006). Supercritical fluid extraction and fractionation of natural matter. The Journal of Supercritical Fluids, 38(2), 146-166. http://dx.doi.org/10.1016/j.supflu.2006.03.020.

Rozzi, N. L., Singh, R. K., Vierling, R. A., \& Watkins, B. A. (2002). Supercritical fluid extraction of lycopene from tomato processing byproducts. Journal of Agricultural and Food Chemistry, 50(9), 2638-2643. http://dx.doi.org/10.1021/jf011001t. PMid:11958635.

Sabio, E., Lozano, M., Montero de Espinosa, V., Mendes, R. L., Pereira, A. P., Palavra, A. F., \& Coelho, J. A. (2003). Lycopene and beta-carotene extraction from tomato processing waste using supercritical $\mathrm{CO}_{2}$. Industrial \& Engineering Chemistry Research, 42(25), 6641-6646. http://dx.doi.org/10.1021/ie0301233.

Saldana, M. A. D., Zefel, C., Mohamed, M. S., \& Brunner, G. (2002). Extraction of caffeine, theobromine and coca butter from brazilian cocoa beans using supercritical $\mathrm{CO}_{2}$ and ethane. Chemical Engineering Transactions, 2, 447-482.

Stewart, A. J., Bozonnet, S., Mullen, W., Jenkins, G. I., Lean, M. E., \& Crozier, A. (2000). Occurrence of flavonols in tomatoes and tomatobased products. Journal of Agricultural and Food Chemistry, 48(7), 2663-2669. http://dx.doi.org/10.1021/jf000070p. PMid:10898604.

Story, E. N., Kopec, R. E., Schwartz, S. J., \& Harris, G. K. (2010). An Update on the Health Effects of Tomato Lycopene. Annual Review of
Food Science and Technology, 1(1), 189-210. http://dx.doi.org/10.1146/ annurev.food.102308.124120. PMid:22129335.

Toor, R. K., \& Savage, G. P. (2005). Antioxidant activity in different fractions of tomatoes. Food Research International, 38(5), 487-494. http://dx.doi.org/10.1016/j.foodres.2004.10.016.

Topal, U., Sasaki, M., Goto, M., \& Hayakawa, K. (2006). Extraction of lycopene from tomato skin with supercritical carbon dioxide: effect of operating conditions and solubility analysis. Journal of Agricultural and Food Chemistry, 54(15), 5604-5610. http://dx.doi.org/10.1021/ jf0606407. PMid:16848552.

Vinha, A. F., Barreira, S. V., Costa, A. S., Alves, R. C., \& Oliveira, M. B. (2014). Organic versus conventional tomatoes: influence on physicochemical parameters, bioactive compounds and sensorial attributes. Food and Chemical Toxicology, 67, 139-144. http://dx.doi. org/10.1016/j.fct.2014.02.018. PMid:24569070.

Visioli, F., Riso, P., Grande, S., Galli, C., \& Porrini, M. (2003). Protective activity of tomato products on in vivo markers of lipid oxidation. European Journal of Nutrition, 42(4), 201-206. http://dx.doi. org/10.1007/s00394-003-0415-5. PMid:12923651.

Yi, C., Shi, J., Xue, S., Jiang, Y., \& Li, D. (2009). Effects of supercritical fluid extraction parameters on lycopene yield and antioxidant activity. Food Chemistry, 113(4), 1088-1094. http://dx.doi.org/10.1016/j. foodchem.2008.08.083. 